\title{
The Potential of Immersive Virtual Reality for Cognitive Training in Elderly
}

\author{
Anna Cornelia Maria Bauer ${ }^{a}$ Gerda Andringa ${ }^{a, b}$ \\ ${ }^{a}$ Department of Science, University College Roosevelt, Utrecht University, Middelburg, The Netherlands; \\ ${ }^{\mathrm{b}}$ Academic Workplace for the Elderly in Zeeland, Middelburg, The Netherlands
}

\section{Keywords}

Virtual reality · Elderly · Cognition - Cognitive decline ·

Training · Dementia

\begin{abstract}
The number of elderly is growing rapidly, including those that struggle with cognitive decline and, consequently, activities of daily living. Developing interventions that slow down cognitive decline would greatly benefit the autonomy of these elderly, as well as their caretakers. Virtual reality (VR) is an immersive and interactive human-computer interface with real-time simulation that is suggested to be a promising tool to improve cognitive functioning. This literature review discusses the features of immersive VR, including its opportunities and limitations, that are of special relevance for improving cognition in elderly. First, the high flexibility of VR allows for personalized and safe training of potentially harmful situations and isolated aspects of tasks. Second, VR's dynamic and real-time feedback on performance provides a labor-extensive tool for caretakers in elderly care. Third, the acquisition of high resolution data enables the exposure of subtle changes over time, relevant for detecting the nature and extent of cognitive changes in elderly, including those
\end{abstract}

\begin{tabular}{ll}
\hline karger@karger.com & $\begin{array}{l}\text { (C) } 2020 \text { The Author(s) } \\
\text { Published by S. Karger AG, Basel } \\
\text { www.karger.com/ger }\end{array}$ \\
Karger & $\begin{array}{l}\text { This article is licensed under the Creative Commons Attribution- } \\
\text { NonCommercial-NoDerivatives 4.0 International License (CC BY- } \\
\text { NC-ND) (http://www.karger.com/Services/OpenAccessLicense). } \\
\text { Usage and distribution for commercial purposes as well as any dis- } \\
\text { tribution of modified material requires written permission. }\end{array}$ \\
BOPEN ACCESS &
\end{tabular}

with dementia. Fourth, immersive VR has been related to cybersickness. Finally, VR is immersive and enables the perception and expression of emotions, motor behaviors, and multiple senses. Aged subjects are found to have sparing of emotional learning and show increased reliance on multisensory integration for learning. Moreover, they experience high levels of flow, motivation, and presence in VR setups. Despite the clear potential of immersive VR, the studies available are small scale and have not been replicated. The digital illiteracy of elderly and healthcare personnel form an additional barrier for implementation. Hence, while replication of outcomes and standardization of VR interventions is required before it can be used in standard care, VR may provide a particularly effective tool for training cognition in elderly.

$$
\begin{aligned}
& \text { ๑ } 2020 \text { The Author(s) } \\
& \text { Published by S. Karger AG, Basel }
\end{aligned}
$$

\section{Introduction}

The European population is aging, and while many remain vital growing older [1], there is an increasing number of European Union citizens that experience age-related diseases [2] and cognitive [3] and physical decline [4]. Indeed, dementia is the second largest cause of disability 
in individuals over 70 years of age [5]. Dementia affects a broad range of cognitive functions, including long-term memory, executive functioning, and spatial orientation [6]. The deterioration of these functions has a detrimental effect on the execution of activities of daily living (ADLs) [7]. The subsequent decrease in autonomy has been associated with a lower quality of life [8]. No intervention has yet fully succeeded in halting the cognitive decline elderly experience. However, cognitive training has been shown to mildly improve global cognition in healthy elderly $[9,10]$ and those with dementia $[9,11,12]$. Moreover, physical interventions, such as resistance training [13-15], alone, or in combination with cognitive interventions, have shown similar positive outcomes in healthy [16-19] and cognitively impaired [18, 20-22] elderly. Unfortunately, improvements are often small and not all studies find a positive effect [23-26].

A novel and promising tool to improve cognitive functioning is immersive virtual reality (VR). VR is eloquently defined by Burdea and Coiffet [27] as follows: "VR is a high-end user-computer interface involving real-time stimulation and interactions of an embedded subject through multiple sensorial channels (visual and auditory, sometimes haptic, even smell and taste if possible), based on a synthetic environment in which the subject feels his presence" [27]. Traditionally speaking, non-immersive VR is considered to be a desktop setting with or without addition of sound. Immersive VR on the other hand, means that the participant wears a head-mounted device (HMD) or is in a cave automatic virtual environment (CAVE). Immersiveness is related to the number of senses involved, their level of involvement, as well as the level of (motor) interaction that is required. Immersive VR allows for flexible, personalized, and safe multimodal training. It does so using a naturalistic setting and real-time sensorial feedback, allowing for immersion to occur. It is these aspects of immersive VR that provide a highly effective learning environment that can potentially be used to facilitate cognitive training.

While VR has been used in elderly populations in a number of studies to train physical health [28-32] or improve intervention attractiveness [33,34], few studies have applied immersive VR in elderly with the aim to improve cognitive skills. Indeed, the suggested digital illiteracy may have contributed to this [35]. At the same time, VR might provide an affordable and effective alternative for training cognitive functions in elderly. Therefore, the aim of this literature review is to discuss the potential opportunities and limitations of immersive VR for improving cognition in elderly. We use the body of

Immersive Virtual Reality for Cognitive Training in Elderly knowledge on VR obtained in quantitative, empirical group, but not case studies. Given the limited number of studies performed in elderly and the heterogeneity of variables used, we do not compare effect sizes between studies. Instead we include a variety of age groups and training settings, and identify which features may be of relevance to elderly, as a group with its own needs and characteristics.

\section{VR Features}

As compared to conventional computer-based devices, VR offers a number of features that provide many rather unique opportunities, but it has a number of limitations as well.

VR Allows for a Highly Flexible Training Environment

The VR environment is highly flexible and allows for the training in settings that are either impossible in real life or too dangerous. It allows for the practicing of a task's constituent parts, before tackling the task in its whole complexity. For instance, a double-blind, randomized controlled study showed that in adults with hemiparetic stroke, isolated aspects of walking, namely weight shifting and stepping, can be subsequently trained and improved [36]. VR can also be used to provide a simplification of reality by removing elements such as gravity [37]. As a participant's skill level increases, these factors can easily be reintegrated into the virtual world, showing VR can cater to the participant's physical abilities, taking into account physical limitations [37]. Next to training in settings that do not exist in real life, VR is especially suitable for providing an environment where situations conceived as potentially dangerous in real life can be trained safely [38]. Many age groups, including elderly, can benefit from such a safe environment. For example, VR enables blind participants $[39,40]$ and wheelchair users $[37,41]$ to practice their visuo-spatial orientation safely, without bumping into their surroundings. Similarly, elderly [42], stroke patients [43], and children [44] can practice crossing the street before doing so in real life. Other examples of executing ADLs in the VR world include preparing food $[45,46]$, going to the supermarket, or walking through a city [47].

The flexibility of VR also means that training settings can be tailored to the participant's individual needs and level in a dynamic fashion. A wide variety of variables can be adjusted such as which [37] and how many [48] stimuli are presented, the size and closeness of these stimuli 
[49], as well as their speed and order [49], while engaged in the training. This use of immediate feedback on performance can ensure the tight fitting of the difficulty setting to the subjects capability [50]. This personalization of VR has proven to be of value in a wide variety of populations such as the blind [39], wheelchair users [37], children [51], stroke patients [52], and is of special relevance for the elderly population [53]. Indeed in elderly, more so than in most other groups, large differences in cognitive and physical fitness exist, underscoring the need for personalization [54]. In addition, functional fitness within the elderly person may decline $[55,56]$, due to normal ageing processes or degenerative processes, meaning that exercise settings require adjustment [57].

To conclude, VR training can be adjusted to the changing abilities of elderly, helping them to train complex tasks step by step and allowing for the training of potentially dangerous situations that are relevant for autonomy. Moreover, VR can be highly personalized. These factors may help prevent training-related injury. This is of special relevance given the increased frailty of elderly and its associated risks, such as falling.

VR Has the Potential to Decrease Dependence on Care Professionals

Commonly, rehabilitation and other training programs are time-consuming for elderly and their informal caretakers, as they require visiting a professional, and are labor extensive for care professionals, as they require individual instruction and guidance. The randomized controlled study by Yang et al. [50] shows that VR rehabilitation of elderly within their community setting is in fact feasible and effective. Moreover, a nonimmersive VR study aimed at reducing falls in older adults [58] suggests that remote group interventions are attainable, however, this needs to be established still for immersive VR settings. While the latter studies indeed confirm that the use of VR may add to the autonomy of elderly, it may be limited to those sufficiently independent and digitally literate. Moreover, these setups still do require labor intensive guidance by care professionals. To date, studies make recommendations $[46,59,60]$ for remote guidance of immersive VR by elderly from their residential setting, but implementation is lacking. The replacement of human supervision, by means of a virtual coach, has been evaluated [61] but not widely studied. To conclude, while VR applications have been shown to increase autonomy of a subset of elderly, its potential to reduce workload of care professionals needs to be explored further [62].

\section{VR Allows for the Gathering of Rich Data}

VR enables a wide variety of data to be gathered with a high temporal resolution, aiding the detection of subtle changes within and between subjects. For example, kinematic data can be gathered, such as stride duration, step width, and mass trajectories [63]. Moreover, the motions tracked can be compared to the ideal execution of a movement. This so-called "motion matching" can help the participant finetune their actions to the desired movement through immediate visual feedback [64].

Lastly, VR can be combined with other techniques such as fMRI, making brain functionality trackable while in the VR environment, giving more valuable insights into VR's effects [65].

The measuring of a wide variety of parameters with a great time resolution is not only of relevance for measuring physical performance, but is also becoming increasingly informative for cognitive performance of functions such as working memory and sensorimotor integration. Being able to measure subtle cognitive changes may help diagnostic as well as training and rehabilitation settings, warranted the data obtained are valid and reliable. Some studies have validated psychometric $[66,67]$ data obtained with immersive VR setups, but more extensive comparison to gold standards for assessment of cognitive functions, such as validated and reliable neuropsychological tests, is needed.

\section{Immersiveness May Cause Cybersickness}

Cybersickness is a problem unique to immersive VR and is characterized by oculomotor symptoms, disorientation, and nausea [68]. In the vast majority of immersive VR studies performed in elderly, the incidence and ratings of cybersickness symptoms are low [69-73]. Some studies suggest a higher cybersickness incidence for elderly than young individuals, however, none have been able to show differences that were significant $[74,75]$. Nevertheless, the development of VR environments that enable a high sense of presence and synchronized integration of senses may reduce cybersickness risk and should be the focus of further study [76-78]

\section{Immersiveness of VR Is Beneficial for Training} Outcomes

The level of immersion has been positively related to training outcomes in young adults. A study by Bayyari and Tudoreanu [79] showed that the perception and comprehension of visual data as measured by the counting of targets of 13 students benefited from a three-wall VR CAVE system over a simple monitor or one- and two-wall CAVE 
systems. Similarly, physical tasks, such as tai chi moves, can be taught better using an interactive 3D display than a non-interactive $2 \mathrm{D}$ display [80]. This single-blind study involving 26 students showed that participants in the immersive VR condition, viewing the instructor from four different stereoscopic images, scored higher on both tai chi knowledge and performance. In addition, tasks requiring spatial knowledge, such as the planning of oil well paths, were performed better and faster by young adult participants in a CAVE-like workstation versus a desktop setup, suggesting that spatial understanding increases with higher levels of immersion [81]. Moreover, a higher performance on a three-dimensional chess game was found using an immersive HMD setup versus a desktop setup, which the authors argue to be due to both the greater amount and greater quality of information available for the 24 subjects studied [82]. Additionally, a study by Gutiérrez et al. [83], which had 25 students examine a traumatic brain injury patient in either a VR world, using a HMD or a desktop, found that knowledge gain was significantly higher in the VR group. Another study in which higher knowledge retention was found was conducted by Winn et al. [84], where 13 students trained with immersive VR had higher posttest scores on the topics of water movement, salinity, and tidal cycle as compared to the 13 students who performed the same task in a non-immersive environment. Few studies have also specifically studied the effects of immersion on cognitive improvement in elderly. In 42 elderly stroke victims, immersive VR over a period of 4 weeks, as compared to computerized cognitive training, significantly improved attention and memory in these elderly as measured by neurocognitive tests [85].

However, not all studies have shown training outcomes to be better for immersive than for non-immersive settings. A study in 96 young adults that watched instructional videos under conditions of low and high immersion, yielded no effect of immersion on retention [86]. Moreover, in a supermarket task, testing episodic memory in 25 young adults and 36 elderly using both immersive and non-immersive VR, elderly made significantly more mistakes during the recall phase in the immersive VR condition [74]. Notably, the studies reporting no effect of VR over conventional methods are unidimensional [86] or their methodology is weak [74].

To conclude, the available evidence suggests that immersion is potentially beneficial for a wide variety of cognitive tasks, including tasks involving episodic and semantic memory, spatial knowledge, and working memory. Whether this observation can be generalized to the elderly population requires further study.

Immersive Virtual Reality for Cognitive Training in Elderly
Factors of Immersion That Affect Training

Outcomes

There are a number of personal factors that have been speculated to underly the positive effect of immersion on training outcome, namely the emotional salience of the task, involvement of multiple senses and factors related to reward, such as flow, motivation, and enjoyment.

A factor that is well known to have a major impact on learning is emotional salience (see Tyng et al. for review) [87]. VR's realism not only allows for the evocation [88] and expression [89] of emotions, it does so more effectively than conventional setups [90]. The study by Visch et al. [90] found higher levels of emotion when students watched a 3D movie in a CAVE-like (VR) system than on a conventional rear wall. Emotional salience of learned material may be of special relevance for application in cognitively impaired elderly, as the advantage of emotional learning does not seem to get lost in elderly with age and increased cognitive impairment. Indeed, in highly aged individuals without mental impairments, individuals with mild cognitive impairments, and individuals with dementia, emotional words were remembered better than neutral words [91]. Another factor influencing learning is the involvement of multiple senses. There is considerable evidence that multisensory learning, i.e., integrating visual and auditory input, is more effective than unisensory learning $[92,93]$. In addition, some of this evidence shows that the incorporation of a motor component aids multisensory learning further by decreasing reaction times [94]. Immersive VR, more so than non-immersive settings, can encompass multiple senses as well as motor responses. Additionally, for multisensory integration, the spatial and temporal onset of the stimuli in the different senses have to be close, which is attainable in VR [95]. Intriguingly, there are multiple lines of evidence indicating that aging increases integration across a range of perceptual domains and behaviors (see for review Freiherr et al. [96]; de Dieuleveult et al. [97]). Moreover, multisensory cognitive interventions have already been tested in elderly with and without dementia, and showed positive results on language tests [98], self-feeding behavior [99], anxiety, overall dementia severity, and neuropsychiatric symptoms [100]. These studies underscore the potential of multisensory interventions on training cognition, especially in elderly, and yield further promise for VR as a tool for elderly. However, as VR programs differ considerably from the traditional multisensory training programs, this field warrants further research. 
Immersiveness may also influence the success of cognitive interventions by increasing flow, motivation, or sense of presence. Flow is considered important, as it has been shown to be related to both workout intensity and motivation [101]. Csikszentmihalyi [102] explains flow to be the "holistic sensation present when we act with total involvement". The level of immersion is of relevance for the flow experienced. This is illustrated by a study by Gruzelier et al. [103], where students receiving neurofeedback training in a more immersive setup, a CAVE-like system, reported a higher flow than participants in the desktop VR condition. Flow is suggested to be maintained in elderly. In fact, in the computer game Second Life, higher levels of flow were found in older age groups, with the 56-65 years age group reporting the highest level of flow [104].

A construct related to flow is motivation, which is important for treatment adherence [101] and learning outcomes, as reviewed by Murphy et al. [105]. Some studies report VR setups to provide higher levels of motivation than conventional setups, in both young [106] and elderly subjects [107]. In the latter small-scale study of 8 elderly participants, subjects reported a higher level of intrinsic motivation in an immersive exercise setup than in the non-immersive VR group [107]. However, this difference was small, and the topic warrants further investigation.

Related to motivation is enjoyment, also influencing treatment adherence in elderly [108]. In a study on deaf and hearing children, when playing an immersive game teaching science, the immersive game was reported as significantly more fun than the desktop version [109]. However, a study comparing the effects of an immersive VR setup and a desktop setup in elderly and young adults found no differences in rated usability, which was scored on the subscales, intelligibility, difficulty, pleasantness, input control, and comfort, between these conditions [74].

To conclude, factors that are typical for immersive VR, such as emotional salience and involvement of multiple senses, are known to enhance training outcomes. In addition, a number of studies suggest higher flow, motivation, and enjoyment in immersive VR setups in comparison to non-immersive VR setups, the latter factors being positively related to intervention adherence. As especially elderly show varying rates of compliance to training programs [110], this is an important topic of research.
Factors Allowing for Immersion

Immersion is dependent on the technology with which a person interacts. Hence, for VR setups, technological factors such as the field of view, display resolution, realism of lighting, frame rate, and refresh rate contribute to immersion, and should be optimized for a maximum level of immersion. Of these technological factors, realism is suggested to be of special relevance for immersiveness and thus training outcomes. Realistic VR environments are shown to support the execution of real-life motor tasks more so than less realistic VR environments [111]. In addition, healthy adults report to be more present in a realistic looking VR environment, for example when walking in the VR environment [112] or identifying with a virtual body [113-115]. Apart from a sense of presence, physiological responses, such as the galvanic skin response and heart rate, mimic a real-life response in young adults better when the VR environment is realistic [116].

In sum, preliminary studies suggest realism in VR to elicit more appropriate physiological and behavioral responses within the VR setting as well as aid transfer of knowledge to real-life situations, though evidence is limited [111]. The added value of realism is most likely highly dependent on the task at hand and the subject group studied. This is reflected by the study of Lokka et al. [117]. They created a custom-designed virtual environment for route learning, with adjusted levels of realism and highlighted landmark locations, and compared participants' route recall performance in an unrealistic abstract environment to those in a fully realistic environment. While both young and old participants expressed an initial preference for the realistic virtual environment, performance was better in the custom-designed environment. This observation is in line with the cognitive load theory, hypothesizing that extraneous processing - cognitive processing that does not support the instructional goal, caused by for instance distractions, takes away from the cognitive capacity used for task relevant information. Other studies, using immersive VR classrooms, have underscored this hypothesis [118]. Indeed while decreasing realism, elimination of distracting stimuli may improve cognitive capacity for the task at hand. Moreover, the possibility to replay and freeze the simulation, to focus on certain aspects of the situation and explain when necessary [119], may offer additional means to enhance learning in the VR environment. As elderly have shown deficits in various fields of attention, including dual-tasking, auditory focused attention, spatial searching, interference control and task-switching, this can potentially be overcome or lessened using immersive VR [120]. 


\section{Discussion}

Immersive VR for cognitive training of elderly shows great potential due to its unique characteristics. It can be tailored to the individual, which is important given the heterogeneity of the elderly population and the need for safe training environments. Moreover, VR's high level of automation can potentially lower the burden conventional interventions pose on caretakers and medical staff, and increase the elderly's feeling of autonomy. In addition, VR provides a very rich dataset and allows for a tight tracking of progress and adjustment of treatment focus. While most studies do not focus on elderly, training outcomes are in general higher with immersive VR as compared to other interventions, and high emotional saliency and involvement of multiple senses are likely underlying factors. Overall, as compared to non-immersive interventions, immersive VR appears to create more flow, motivation, and fun, which can play an important role in the intervention adherence of elderly. Lastly, the realism of immersive VR helps transferring acquired skills from the VR environment to real life.

While the potential of immersive VR for training the cognition of elderly is clear, there are many factors that require extensive study before it can be established if, and in what way, immersive VR for cognitive training in elderly can be implemented in standard care. First and foremost, a wide variety of tasks and equipment is used in the currently available studies. In this review, we therefore provide a comprehensive overview rather than a systematic synthesis of these studies. The tasks used are mostly prototypes rather than widely and commercially available interventions. There is also some variation in the equipment, such as the joystick and headset, used. These observations of heterogeneity stress the need for a protocol outlining the minimum requirements for VR setups in order to obtain valid and comparable data and the shared use of promising tasks for replication studies. Secondly, more research should be conducted using elderly as target group, including cognitively healthy elderly as well as elderly in various stages of cognitive decline. Indeed, much of the currently presented research focused on young adults [79-84]. Thirdly, cognition of elderly should be trained using more relevant VR environments. Such environments could train cognitive functions that have been shown to influence ADLs, such as executive function, motor behavior, and memory. Indeed the metaanalysis of Lee et al. [121], on the effects of VR in stroke patients, provides support for VR as an effective tool to improve ADLs. Moreover, the feasibility of training ADLs directly in VR has been shown [122]. Whether improvement of ADLs can be obtained by immersive VR, either indirectly, by training executive function, or directly by training ADLs, is an important topic of future study. Fourth, the lack of familiarity of elderly with technological tools requires adaptation of VR software and hardware. It is recommended to make the navigation through the VR world intuitive, by using, for instance, a joystick rather than a mouse, in order to make the elderly feel comfortable using this technology [122]. For healthy adults, a game in immersive VR showed to be more natural and intuitive than its non-immersive version. However, no research on the effects of more natural and intuitive interactions in immersive VR setups has been conducted in elderly. Fifth, the long-term effects of immersive VR on learning should be examined, as the studies presented focus on single training sessions, and do not include follow-ups [74, 79-84, 86, 123]. Some studies suggest that immersive VR might be overstimulating when using it for the first time, which might interfere with learning. Therefore, initial learning outcomes might differ from long-term learning effects [74, 123, 124]. Hence, it is currently unclear whether greater learning effects occur after multiple sessions, and how robust the knowledge gained is. To promote long-term intervention adherence, the games need to be tailored to the needs and wishes of elderly, using the input of elderly. Finally, considering the fact that elderly, perhaps even more so than young adults, benefit from multisensorial learning, this can be capitalized by offering multisensory environments and tasks to promote learning in elderly.

To conclude, immersive VR seems very promising in training cognition in elderly, but more research with elderly is needed. VR is becoming an inexpensive and readily available tool to be applied by elderly. In return, this might relieve some of the burden on professionals, and will allow more elderly to live a satisfying and autonomous life.

\section{Acknowledgements}

We thank students (Joost Kaptein and Puk Nuijten) and colleagues (Richard van den Doel) of the University College Roosevelt, as well as collaborators (Arend Roos) for their valuable input.

\section{Conflict of Interest Statement}

The authors have no conflicts of interest to declare. 


\section{Funding Sources}

The study was not funded.

\section{Author Contributions}

Anna Cornelia Maria Bauer performed the literature study and wrote the first version of the paper. Gerda Andringa supervised the research and writing process and contributed to the final version of the paper.

\section{References}

1 European Commission (DG ECFIN) and Economic Policy Committee. (Ageing Working Group). The 2018 Ageing Report: economic and budgetary projections for the 28 EU member states (2016-2070). European Economy, No. 79, May 2018; Brussels.

2 Lindgren $B$. The rise in life expectancy, health trends among the elderly, and the demand for health and social care. National Institute of Economic Research, Working Paper. 2016;(142):2016.

3 Dewey ME, Prince MJ. Cognitive Function. In: Börsch-Supan A, Brugiavini A, Jürges $\mathrm{H}$, Mackenbach J, Siegrist J, Weber G, editors. Health, ageing and retirement in Europe first results from the survey of health, ageing and retirement in Europe. Mannheim: MEA; 2005. pp. 118-25.

4 The MOPACT Coordination Team. Declining trends of healthy life years expectancy (HLYE) in Europe.

5 OECD. Addressing dementia: the OECD response. Paris: OECD publishing; 2015.

6 Murman DL. The impact of age on cognition. Semin Hear. 2015 Aug;36(3):111-21.

7 Barberger-Gateau P, Commenges D, Gagnon M, Letenneur L, Sauvel C, Dartigues JF. Instrumental activities of daily living as a screening tool for cognitive impairment and dementia in elderly community dwellers. J Am Geriatr Soc. 1992 Nov;40(11):1129-34.

8 Giebel CM, Sutcliffe C, Stolt M, Karlsson S, Renom-Guiteras A, Soto M, et al. Deterioration of basic activities of daily living and their impact on quality of life across different $\operatorname{cog}$ nitive stages of dementia: a European study. Int Psychogeriatr. 2014 Aug;26(8):1283-93.

9 Giuli C, Papa R, Lattanzio F, Postacchini D. The effects of cognitive training for elderly: results from my mind project. Rejuvenation Res. 2016 Dec;19(6):485-94.

10 Kelly ME, Loughrey D, Lawlor BA, Robertson $\mathrm{IH}$, Walsh C, Brennan S. The impact of cognitive training and mental stimulation on cognitive and everyday functioning of healthy older adults: a systematic review and metaanalysis. Ageing Res Rev. 2014 May;15:28-43.

11 Liu XY, Li L, Xiao JQ, He CZ, Lyu XL, Gao L, et al. Cognitive training in older adults with mild cognitive impairment. Biomed Environ Sci. 2016 May;29(5):356-64.

12 Hill NT, Mowszowski L, Naismith SL, Chadwick VL, Valenzuela M, Lampit A. Computerized cognitive training in older adults with mild cognitive impairment or dementia: a systematic review and meta-analysis. Am J Psychiatry. 2017 Apr;174(4):329-40.
13 Li Z, Peng X, Xiang W, Han J, Li K. The effect of resistance training on cognitive function in the older adults: a systematic review of randomized clinical trials. Aging Clin Exp Res. 2018 Nov;30(11):1259-73.

14 Zhang Y, Li C, Zou L, Liu X, Song W. The effects of mind-body exercise on cognitive performance in elderly: a systematic review and meta-analysis. Int $\mathrm{J}$ Environ Res Public Health. 2018 Dec;15(12):2791.

15 Northey JM, Cherbuin N, Pumpa KL, Smee DJ, Rattray B. Exercise interventions for cognitive function in adults older than 50: a systematic review with meta-analysis. Br J Sports Med. 2018 Feb;52(3):154-60.

16 van het Reve E, de Bruin ED. Strength-balance supplemented with computerized cognitive training to improve dual task gait and divided attention in older adults: a multicenter randomized-controlled trial. BMC Geriatr. 2014 Dec;14(1):134.

17 Lauenroth A, Ioannidis AE, Teichmann B. Influence of combined physical and cognitive training on cognition: a systematic review. BMC Geriatr. 2016 Jul;16(1):141.

18 Bruderer-Hofstetter M, Rausch-Osthoff AK, Meichtry A, Münzer T, Niedermann K. Effective multicomponent interventions in comparison to active control and no interventions on physical capacity, cognitive function and instrumental activities of daily living in elderly people with and without mild impaired cognition - A systematic review and network meta-analysis. Ageing Res Rev. 2018 Aug;45: $1-14$

19 Theill N, Schumacher V, Adelsberger R, Martin M, Jäncke L. Effects of simultaneously performed cognitive and physical training in older adults. BMC Neurosci. 2013 Sep;14(1):103.

20 McEwen SC, Siddarth P, Rahi B, Kim Y, Mui $\mathrm{W}, \mathrm{Wu}$ P, et al. Simultaneous aerobic exercise and memory training program in older adults with subjective memory impairments. J Alzheimers Dis. 2018;62(2):795-806.

21 Maffei L, Picano E, Andreassi MG, Angeluci A, Baldacci F, Baroncelli L, et al.; Train the Brain Consortium. Randomized trial on the effects of a combined physical/cognitive training in aged MCI subjects: the Train the Brain study. Sci Rep. 2017 Jan;7(1):39471.

22 Sherman DS, Mauser J, Nuno M, Sherzai D. The efficacy of cognitive intervention in mild cognitive impairment (MCI): a meta-analysis of outcomes on neuropsychological measures. Neuropsychol Rev. 2017 Dec;27(4): $440-84$.
23 de Souto Barreto P, Demougeot L, Vellas B, Rolland Y. Exercise training for preventing dementia, mild cognitive impairment, and clinically meaningful cognitive decline: a systematic review and meta-analysis. I Gerontol A Biol Sci Med Sci. 2018 Oct; 73(11):1504-11

24 Gates N, Fiatarone Singh MA, Sachdev PS, Valenzuela $\mathrm{M}$. The effect of exercise training on cognitive function in older adults with mild cognitive impairment: a meta-analysis of randomized controlled trials. Am J Geriatr Psychiatry. 2013 Nov;21(11):1086-97.

25 Zhang H, Huntley J, Bhome R, Holmes B, Cahill J, Gould RL, et al. Effect of computerised cognitive training on cognitive outcomes in mild cognitive impairment: a systematic review and meta-analysis. BMJ Open. 2019 Aug;9(8):e027062.

26 Eggenberger P, Schumacher V, Angst M, Theill N, de Bruin ED. Does multicomponent physical exercise with simultaneous cognitive training boost cognitive performance in older adults? A 6-month randomized controlled trial with a 1-year follow-up. Clin Interv Aging. 2015 Aug;10:1335-49.

27 Burdea GC, Coiffet P. Virtual reality technology. John Wiley \& Sons; 2003. https://doi. org/10.1162/105474603322955950.

28 Tsang WW, Fu AS. Virtual reality exercise to improve balance control in older adults at risk of falling. Hong Kong Med J. 2016 Feb;22 Suppl 2:S19-22.

29 Kamińska MS, Miller A, Rotter I, Szylińska A, Grochans E. The effectiveness of virtual reality training in reducing the risk of falls among elderly people. Clin Interv Aging. 2018 Nov; 13:2329-38.

30 In T, Lee K, Song C. Virtual reality reflection therapy improves balance and gait in patients with chronic stroke: randomized controlled trials. Med Sci Monit. 2016 Oct;22: 4046-53.

31 Donath L, Rössler R, Faude O. Effects of virtual reality training (exergaming) compared to alternative exercise training and passive control on standing balance and functional mobility in healthy community-dwelling seniors: a meta-analytic review. Sports Med. 2016 Sep;46(9):1293-309.

32 Yang WC, Wang HK, Wu RM, Lo CS, Lin $\mathrm{KH}$. Home-based virtual reality balance training and conventional balance training in Parkinson's disease: A randomized controlled trial. J Formos Med Assoc. 2016 Sep;115(9): $734-43$ 
33 Laufer Y, Dar G, Kodesh E. Does a Wii-based exercise program enhance balance control of independently functioning older adults? A systematic review. Clin Interv Aging. 2014 Oct;9:1803-13.

34 Syed-Abdul S, Malwade S, Nursetyo AA, Sood M, Bhatia M, Barsasella D, et al. Virtual reality among the elderly: a usefulness and acceptance study from Taiwan. BMC Geriatr. 2019 Aug;19(1):223.

35 Amaral I, Daniel F. Ageism and IT: social representations, exclusion and citizenship in the digital age. In: Zhou J, Salvendy G, editors. Human aspects of IT for the aged population. Healthy and active aging. Toronto: Springer; 2016. p. 159-66. https://doi.org/10.1007/9783-319-39949-2_15.

36 Kim JH, Jang SH, Kim CS, Jung JH, You JH. Use of virtual reality to enhance balance and ambulation in chronic stroke: a double-blind, randomized controlled study. Am J Phys Med Rehabil. 2009 Sep;88(9):693-701.

37 Cooper RA, Ding D, Simpson R, Fitzgerald SG, Spaeth DM, Guo S, et al. Virtual reality and computer-enhanced training applied to wheeled mobility: an overview of work in Pittsburgh. Assist Technol. 2005;17(2):15970.

38 Botella C, Quero S, Baños RM, Perpiñá C, García Palacios A, Riva G. Virtual reality and psychotherapy. Stud Health Technol Inform. 2004;99:37-54.

39 Lahav O, Mioduser D. Multisensory virtual environment for supporting blind persons' acquisition of spatial cognitive mapping: a case study. In: Proceedings of ED-MEDIA 2001 - World Conference on Educational Multimedia, Hypermedia \& Telecommunications. Norfolk, USA: Association for the Advancement of Computing in Education (AACE); 2001. p. 1046-51.

40 Lahav O, Schloerb DW, Srinivasa MA. Virtual environment system in support of a traditional orientation and mobility rehabilitation program for people who are blind. Presence: Teleoperators and Virtual Environments. 2013;22(3):235-54.

41 Harrison A, Derwent G, Enticknap A, Rose FD, Attree EA. The role of virtual reality technology in the assessment and training of inexperienced powered wheelchair users. Disabi Rehabil. 2002 Jul;24(11-12):599-606.

42 Maillot P, Dommes A, Dang NT, Vienne F. Training in the elderly in pedestrian safety: Transfer effect between two virtual reality simulation device. Accid Anal Prev. 2017 Feb; 99(Pt A):161-70.

43 Katz N, Ring H, Naveh Y, Kizony R, Feintuch $\mathrm{U}$, Weiss PL. Interactive virtual environment training for safe street crossing of right hemisphere stroke patients with unilateral spatial neglect. Disabil Rehabil. 2005 Oct;27(20): 1235-43.

44 Schwebel DC, Gaines J, Severson J. Validation of virtual reality as a tool to understand and prevent child pedestrian injury. Accid Anal Prev. 2008 Jul;40(4):1394-400.
45 Rizzo A, Kim GJ. A SWOT analysis of the field of virtual reality rehabilitation and therapy. Presence: Virtual and Augmented Reality. 2005; 14(2): 119-46. https://doi. org/10.1162/1054746053967094.

46 Gourlay D, Lun KC, Lee YN, Tay J. Virtual reality for relearning daily living skills. Int J Med Inform. 2000 Dec;60(3):255-61.

47 Atkins AS, Stroescu I, Spagnola NB, Davis VG, Patterson TD, Narasimhan M, et al. Assessment of age-related differences in functional capacity using the virtual reality functional capacity assessment tool (VRFCAT). J Prev Alzheimers Dis. 2015 Jun;2(2):121-7.

48 Schultheis MT, Rizzo AA. The application of virtual reality technology in rehabilitation. Rehabil Psychol. 2001;46(3):296-311.

49 Ma M, McNeill M, Charles D, Mcdonough S, Crosbie J, Oliver L, et al. Adaptive virtual reality games for rehabilitation of motor disorders. In: International Conference on Universal Access in Human-Computer interaction. Berlin, Germany: Springer, 2007. p. 681-90.

50 Yang YR, Tsai MP, Chuang TY, Sung WH, Wang RY. Virtual reality-based training improves community ambulation in individuals with stroke: a randomized controlled trial. Gait Posture. 2008 Aug;28(2):201-6.

51 Rosenfield N, Lamkin K, Re J, Day K, Boyd L, Linstead E. A virtual reality system for practicing conversation skills for children with autism. Multimodal Technologies Interact. 2019;3(2):28.

52 Merians AS, Jack D, Boian R, Tremaine M, Burdea GC, Adamovich SV, et al. Virtual reality-augmented rehabilitation for patients following stroke. Phys Ther. 2002 Sep;82(9): 898-915.

53 Bisson EJ, Contant B, Sveistrup H, Lajoie Y. Balance training for elderly: comparison between virtual reality and visual biofeedback. J Aging Phys Act. 2004;12(3):337.

54 Wilson RS, Beckett LA, Barness LL, Schneider JA, Bach J, Evans DA, et al. Individual differences in rates of change in cognitive abilities of older persons. Psychol Aging. 2002 Jun; 17(2):179-93.

55 Milanović Z, Pantelić S, Trajković N, Sporiš G, Kostić R, James N. Age-related decrease in physical activity and functional fitness among elderly men and women. Clin Interv Aging. 2013;8:549-56.

56 Kohrt WM, Malley MT, Coggan AR, Spina RJ Ogawa T, Ehsani AA, et al. Effects of gender, age, and fitness level on response of VO2max to training in 60-71 yr olds. J Appl Physiol (1985). 1991 Nov;71(5):2004-11.

57 Mazzeo RS, Tanaka H. Exercise prescription for the elderly: current recommendations. Sports Med. 2001;31(11):809-18.

58 Mirelman A, Rochester L, Maidan I, Del Din S, Alcock L, Nieuwhof F, et al. Addition of a non-immersive virtual reality component to treadmill training to reduce fall risk in older adults (V-TIME): a randomised controlled trial. Lancet. 2016 Sep;388(10050):1170-82.
59 Optale G, Urgesi C, Busato V, Marin S, Piron $\mathrm{L}$, Priftis K, et al. Controlling memory impairment in elderly adults using virtual reality memory training: a randomized controlled pilot study. Neurorehabil Neural Repair. 2010 May;24(4):348-57.

60 Vogiatzaki E, Kruwoski A. Rehabilitation after stroke using immersive user interfaces in $3 \mathrm{D}$ virtual and augmented gaming environments. EAI Endorsed Transactions on Pervasive Health and Technology. 2015 May; doi: 10.4108/phat.1.1.e7.

61 Kim J, Son J, Ko N, Yoon B. Unsupervised virtual reality-based exercise program improves hip muscle strength and balance control in older adults: a pilot study. Arch Phys Med Rehabil. 2013 May;94(5):937-43.

62 Chappell NL, Novak M. The role of support in alleviating stress among nursing assistants. Gerontologist. 1992 Jun;32(3):351-9.

63 Fung J, Perez CF. Sensorimotor enhancement with a mixed reality system for balance and mobility rehabilitation. Annual International Conference of the IEEE Engineering in Medicine and Biology Society. 2011;2011:6753-7. doi: 10.1109/IEMBS.2011.6091666.

64 Chan J, Leung H, Tang J, Komura T. A virtual reality dance training system using motion capture technology. IEEE Trans Learn Technol. 2011;4(2):187-95.

65 Spiers HJ, Maguire EA. Spontaneous mentalizing during an interactive real world task: an fMRI study. Neuropsychologia. 2006;44(10): 1674-82.

66 Matheis RJ, Schultheis MT, Tiersky LA, DeLuca J, Millis SR, Rizzo A. Is learning and memory different in a virtual environment? Clin Neuropsychol. 2007 Jan;21(1):146-61.

67 Henry M, Joyal CC, Nolin P. Development and initial assessment of a new paradigm for assessing cognitive and motor inhibition: the bimodal virtual-reality Stroop. J Neurosci Methods. 2012 Sep;210(2):125-31.

68 Kennedy RS, Lane NE, Berbaum KS, Lilienthal MG. Simulator sickness questionnaire: an enhanced method for quantifying simulator sickness. Int J Aviat Psychol. 1993;3(3): 203-20.

69 Benham S, Kang M, Grampurohit N. Immersive virtual reality for the management of pain in community-dwelling older adults. OTJR (Thorofare NJ). 2019 Apr;39(2):90-6.

70 Lecavalier NC, Ouellet E, Boller B, Belleville S. Use of immersive virtual reality to assess episodic memory: A validation study in older adults. Neuropsychol Rehabil. 2018:1-19. Epub 2018 May 29.

71 Huygelier H, Schraepen B, van Ee R, Vanden Abeele V, Gillebert CR. Acceptance of immersive head-mounted virtual reality in older adults. Sci Rep. 2019 Mar;9(1):4519.

72 Robertson S, Hanson M, McCabe PT. Contemporary ergonomics 2000. London: CRC Press; 2000. [cited $2020 \mathrm{Feb} 7$ ]. Available from: https:// books.google.nl/books?id=iUtZDwAAQBAJ\& printsec $=$ frontcover $\& \mathrm{hl}=\mathrm{nl} \# \mathrm{v}=$ onepage $\& \mathrm{q} \& \mathrm{f}=$ false https://doi.org/10.1201/9781482289336. 
73 Park GD, Allen RW, Fiorentino D, Rosenthal TJ, Cook ML. Simulator sickness scores according to symptom susceptibility, age, and gender for an older driver assessment study. Proc Hum Factors Ergon Soc Annu Meet. 2006;50(26):2702-6.

74 Plechatá A, Sahula V, Fayette D, Fajnerová I. Age-related differences with immersive and non-immersive virtual reality in memory assessment. Front Psychol. 2019 Jun;10:1330.

75 Arns LL, Cerney MM. The relationship between age and incidence of cybersickness among immersive environment users. IEEE Proceedings. Virtual Reality, 2005. Available from:https://doi.org/10.1109/vr.2005.1492788.

76 Palmisano S, Mursic R, Kim J. Vection and cybersickness generated by head-and-display motion in the oculus rift. Displays. 2017;46: $1-8$.

77 Liu CL, Uang ST. Effects of depth perception cues and display types on presence and cybersickness in the elderly within a $3 \mathrm{D}$ virtual store. J Ambient Intell Humaniz Comput. 2015;7(6):763-75.

78 Weech S, Kenny S, Barnett-Cowan M. Presence and cybersickness in virtual reality are negatively related: a review. Front Psychol. 2019 Feb;10:158.

79 Bayyari A, Tudoreanu M. The impact of immersive virtual reality displays on the understanding of data visualization. In: Proceedings of the ACM Symposium on Virtual Reality Software and Technology. Limassol, Cyprus. 2006:368-371.

80 Patel K, Bailenson JN, Hack-Jung S, Diankov R, Bajcsy R. The effects of fully immersive virtual reality on the learning of physical tasks. In: Proceedings of PRESENCE 2006: the 9th Annual International Workshop on Presence. Cleveland, USA. 2006:87-94.

81 Gruchalla K. Immersive well-path editing: investigating the added value of immersion. IEEE Virtual Reality. 2004;2004:157-64.

82 Slater M, Linakis V, Usoh M, Kooper R. Immersion, presence and performance in virtual environments: an experiment with tri-dimensional chess. In: Proceedings of the ACM Symposium on Virtual Reality Software and Technology. 1996:163-172.

83 Gutiérrez F, Pierce J, Vergara VM, Coulter R, Saland L, Caudell TP, et al. The effect of degree of immersion upon learning performance in virtual reality simulations for medical education. Stud Health Technol Inform. 2007;125:155-60.

84 Winn W, Windschitl M, Fruland R. When does immersion in a virtual environment help students construct understanding? In: Proceedings of the International Conference of the Learning Sciences, ICLS. 2002:497-503.

85 Cho DR, Lee SH. Effects of virtual reality immersive training with computerized cognitive training on cognitive function and activities of daily living performance in patients with acute stage stroke: A preliminary randomized controlled trial. Medicine (Baltimore). 2019 Mar;98(11):e14752.
86 Buttussi F, Chittaro L. Effects of different types of virtual reality display on presence and learning in a safety training scenario. IEEE Trans Vis Comput Graph. 2018 Feb; 24(2):1063-76.

87 Tyng CM, Amin HU, Saad MNM, Malik AS. The influences of emotion on learning and memory. Front Psychol 2017 Aug. https:// doi.org/10.3389/fpsyg.2017.01454.

88 Wiederhold BK, Wiederhold MD. Lessons learned from 600 virtual reality sessions. Cyberpsychol Behav. 2000;3(3):393-400.

89 Riva G, Mantovani F, Capideville CS, Preziosa A, Morganti F, Villani D, et al. Affective interactions using virtual reality: the link between presence and emotions. Cyberpsychol Behav. 2007 Feb;10(1):45-56.

90 Visch VT, Tan ES, Molenaar D. The emotional and cognitive effect of immersion in film viewing. Cogn Emotion. 2010;24(8): 1439-45.

91 Nieuwenhuis-Mark RE, Schalk K, de Graaf $\mathrm{N}$. Free recall and learning of emotional word lists in very elderly people with and without dementia. Am J Alzheimers Dis Other Demen. 2009 Apr-May;24(2):155-62.

92 Shams L, Seitz AR. Benefits of multisensory learning. Trends Cogn Sci. 2008 Nov; 12(11): 411-7.

93 Murray MM, Foxe JJ, Wylie GR. The brain uses single-trial multisensory memories to discriminate without awareness. Neuroimage. 2005 Aug;27(2):473-8.

94 Butler AJ, James TW, James KH. Enhanced multisensory integration and motor reactivation after active motor learning of audiovisual associations. J Cogn Neurosci. 2011 Nov;23(11):3515-28.

95 Koelewijn T, Bronkhorst A, Theeuwes J. Attention and the multiple stages of multisensory integration: A review of audiovisual studies. Acta Psychol (Amst). 2010 Jul; 134(3):372-84.

96 Freiherr J, Lundström JN, Habel U, Reetz K. Multisensory integration mechanisms during aging. Front Hum Neurosci. 2013 Dec;7: 863.

97 de Dieuleveult AL, Siemonsma PC, van Erp JB, Brouwer AM. Effects of aging in multisensory integration. Front Aging Neurosci. 2017 Mar;9:80.

98 de Macedo LD, De Oliveira TC, Soares FC, Bento-Torres J, Bento-Torres NV, Anthony DC, et al. Beneficial effects of multisensory and cognitive stimulation in institutionalized elderly: 12-months follow-up. Clin Interv Aging. 2015 Aug;10:1351-9.

99 Hames-Hahn CS, Llorens LA. Impact of a multisensory occupational therapy program on components of self-feeding behaviour in elderly. Phys Occup Ther Geriatr. 1989;6(34):63-86.

100 Sánchez A, Maseda A, Marante-Moar MP, de Labra C, Lorenzo-López L, Millán-Calenti JC. Comparing the effects of multisensory stimulation and individualized music sessions on elderly people with severe demen- tia: a randomized controlled trial. J Alzheimers Dis. 2016 Mar;52(1):303-15.

101 Finkelstein S, Nickel A, Lipps Z, Barnes T, Wartell Z, Suma EA. Astrojumper: motivating exercise with an immersive virtual reality exergame. Presence: Teleoperators and Virtual Environment. 2011;20(1):78-92.

102 Csikszentmihalyi M. Flow and the foundations of positive psychology: the collected works of Mihaly Csikszentmihalyi. Dordrecht: Springer Netherlands; 2014. https:// doi.org/10.1007/978-94-017-9088-8.

103 Gruzelier J, Inoue A, Smart R, Steed A, Steffert $T$. Acting performance and flow state enhanced with sensory-motor rhythm neurofeedback comparing ecologically valid immersive VR and training screen scenarios. Neurosci Lett. 2010 Aug;480(2):112-6.

104 Faiola A, Newlon C, Pfaff M, Smyslova O. Correlating the effects of flow and telepresence in virtual worlds: enhancing our understanding of user behaviour in game-based learning. Comput Human Behav. 2013; 29(3):1113-21.

105 Murphy C, Chertoff D, Guerrero M, Moffitt K. Design better games: flow, motivation, and fun in learning games. In: Coleman S, Hussain T, editors. Design and Development of Training Games: Practical Guidelines from a Multidisciplinary Perspective. Chapter 5, Cambridge University Press; 2015. p. 146-78. doi: 10.1017/СBO9781107280137.007.

106 Parong J, Mayer RE. Learning science in immersive virtual reality. J Educ Psychol. 2018; 110(6):785-97.

107 Bruun-Pedersen JR, Serafin S, Kofoed LB. Going outside while staying inside: exercise motivation with immersive vs. non-immersive recreational virtual environment augmentation for older adult nursing home residents. In: IEEE International Conference on Healthcare Informatics (ICHI 2016). Chicago, USA; 2016. p. 216-26.

108 Ryan RM, Frederick CM, Lepes D, Rubio N Sheldon KM. Intrinsic motivation and exercise adherence. Int J Sport Psychol. 1997; 28(4):335-54

109 Adamo-Villani N, Wilburg RB. Effects of platform (immersive versus non-immersive) on usability and enjoyment of a virtual learning environment for deaf and hearing children. In: 14th Eurographics Symposium on Virtual Environments. Eindhoven, The Netherlands: The Eurographics Associationk; 2008. p. 17-20.

110 Boot WR, Champion M, Blakely DP, Wright T, Souders DJ, Charness N. Video games as a means to reduce age-related cognitive decline: attitudes, compliance, and effectiveness. Front Psychol. 2013 Feb;4:31.

111 Cooper N, Milella F, Cant I, Pinto C, White M, Meyer G. Augmented cues facilitate learning transfer from virtual to real environments. In: 2016 IEEE International Symposium on Mixed and Augmented Reality (ISMARAdjunct). 2016. p. 194-98. https://doi.org/ 10.1109/ISMAR-Adjunct.2016.0075. 
112 Lee J, Jinmo K. A study on immersion and VR sickness in walking interaction for immersive virtual reality applications. Symmetry (Basel). 2017;9(5):78.

113 Slater M, Usoh M, Steed A. Taking steps: the influence of a walking technique on presence in virtual reality. Lancet Infect Dis. 2014;14(7):561.

114 Slater M, Usoh M. Representations systems, perceptual position, and presence in immersive virtual environments. Presence (Camb Mass). 1993;2(3):221-33.

115 Kilteni K, Normand JM, Sanchez-Vives MV, Slater M. Extending body space in immersive virtual reality: a very long arm illusion. PLoS ONE. 2012;7(7):e40867. https://doi. org/10.1371/journal.pone.0040867.

116 Slater M, Khanna P, Mortensen J, Yu I. Visual realism enhances realistic response in an immersive virtual environment. IEEE Comput Graph Appl. 2009 May-Jun;29(3): 76-84.
117 Lokka IE, Çöltekin A, Wiener J, Fabrikant SI, Röcke C. Virtual environments as memory training devices in navigational tasks for older adults. Sci Rep. 2018 Jul;8(1):10809.

118 Strickland D. Virtual reality for the treatment of autism. Stud Health Technol Inform. 1997;44:81-6.

119 Vera L, Campos R, Herrera G, Romero C. Computer graphics applications in the education process of people with learning difficulties. Comput Graph. 2007;31(4):649-58.

120 Zanto TP, Gazzaley A. Attention and ageing. In: Nobre AC, Kastner S, editors. The Oxford Handbook of Attention, Oxford University Press; 2014. pp. 927-71.

121 Lee HS, Park YJ, Park SW. The effects of virtual reality training on function in chronic stroke patients: A systematic review and meta-analysis. BioMed Res Int. 2019 Jun;2019: 7595639.
122 Gerber SM, Muri RM, Mosimann UP, Nef T, Urwyler P. Virtual reality for activities of daily living training in neurorehabilitation: a usability and feasibility study in healthy participants. 2018 40th Annual International Conference of the IEEE Engineering in Medicine and Biology Society (EMBC). 2018;2018:1-4.

123 Bailey J, Bailenson JN, Won AS, Flora J, Armel KC. Presence and memory: immersive virtual reality effects on cued recall. In Proceedings of the International Society for Presence Research Annual Conference. Philadelphia, United States of America. 2012. p. 24-26.

124 Schröder B, Bailey S, Johnson C, GonzalezHolland E. Presence and usability do not directly predict procedural recall in virtual reality training. HCI International 2017 Posters' Extended Abstracts. Vancouver, Canada. 2017. p. 54-61. 